\title{
Effect of two recycled building materials on the density and compressive strength of a clay soil
}

\author{
J. Abregú ${ }^{1}$, C. Mayon², C. Fernández ${ }^{3}$ \\ Engineering School, Universidad Peruana de Ciencias Aplicadas, Lima, Perú \\ ${ }^{1}$ Corresponding author \\ E-mail: ${ }^{1}$ 201413097@upc.edu.pe, ${ }^{2}$ u201413079@upc.edu.pe, ${ }^{3}$ pccicfer@upc.edu.pe
}

Received 2 February 2021; received in revised form 21 February 2021; accepted 2 March 2021 DOI https://doi.org/10.21595/vp.2021.21905

D) Check for updates

Copyright $(C 2021 \mathrm{~J}$. Abregú, et al. This is an open access article distributed under the Creative Commons Attribution License, which permits unrestricted use, distribution, and reproduction in any medium, provided the original work is properly cited.

\begin{abstract}
The objective of this paper is to evaluate the geotechnical performance of a clay soil of high plasticity added with recycled brick powder (RBP) and recycled gypsum powder (RGP), both obtained in "waste" condition. In order to classify the soil, in its natural state, as a clay of high plasticity, the tests of moisture content, granulometry and consistency limits were performed. Subsequently, soil samples were prepared with the two additives proposed in percentages of $2.5 \%, 5 \%$ and $7.5 \%$ of RGP and $5 \%, 10 \%$ and $15 \%$ of RBP. This is in order to evaluate its influence on the dry density and unconfined compressive strength of the soil. Laboratory test results have demonstrated that the inclusion of RGP and RBP produce an increase of up to $7.5 \%$ in soil density and $13.5 \%$ in the optimum soil moisture content compared to the values obtained from natural soil without additions. Furthermore, unconfined compressive strength increased from an average value of $6.3 \mathrm{~kg} / \mathrm{cm}^{2}$ to $28.8 \mathrm{~kg} / \mathrm{cm}^{2}$. These results reflect that the higher the RBP and RGP addition content in the soil, the higher the soil's resistance to compression forces.
\end{abstract}

Keywords: clay soil, brick powder, gypsum, high plasticity, moisture content.

\section{Introduction}

Expansive soils have always been a challenge for the civil engineering industry. This is mainly due to the damage that its volumetric instability can cause in structures that are built on it. This characteristic pattern, different from the rest of soils, depends, mainly, on their moisture content and their mineralogical composition. When the humidity of the soil increases it tends to swell while, if the humidity decreases it tends to retract in a cyclical process that frequently depends on the existing environmental conditions [1]. Furthermore, the volumetric instability of a clay soil also depends on the presence of montmorillonite minerals in its composition. These minerals are characterized by their small particle size, large specific area and high cation exchange capacity, which allows it to retain some of the water that reaches the soil in a space between its particles called interlayer, resulting in an increase in volume of the total soil mass [2].

Furthermore, some authors argue that the construction industry carries with it the greatest environmental impact compared to other productive activities. This is due to the fact that construction processes use various natural resources as raw materials and machinery. This generally involves noise, air and water pollution, and emissions of harmful gases, among others [3]. All the aforementioned contrasts with the fact that in many countries infrastructure projects represent the driving mechanism of their economy and very few companies make real efforts to reduce the environmental impact their activities generate [4].

The present study focuses on reducing the problems of expansive properties caused by clay soils by using the incorporation of elements that generate physical and chemical interactions, as is the case of ceramic powder and recycled gypsum. These elements make possible to reduce changes in volume and improve the resistance to shear stress and the properties of the soil, thus making possible to reuse materials that were initially considered "waste". 


\section{Current state of knowledge}

Soil stabilization consists of improving the properties of the soil so that it responds efficiently to external stresses. To this end, throughout history various materials have been used such as fly ash, ceramic dust, gypsum, cement, lime, etc.

Cabalar, Hassan and Abdulnafaa evaluated the use of ceramic tiles added to the subgrade of a road pavement. These were added at a percentage of $0 \%, 5 \%, 10 \%, 15 \%, 20 \%$, and $30 \%$ respect to the dry weight of the natural soil and subsequently tested for California Bearing Ratio (CBR), Unconfined Compressive Strength (UCS), Compaction, and Free Expansion with Consolidometer. The result of the tests demonstrates that the addition of ceramic tile increases the CBR value of the soil and reduces the value of its unconfined compressive strength. In addition, it generates an increase in dry unit weight and a decrease in the optimum moisture content. Finally, the test results show a decrease in the void ratio with an increase in the amount of ceramic tile waste [5].

Al-Adili, Salim and Al-Soudany evaluate the use of recycled gypsum, extracted from discarded gypsum plasterboards, as a stabilizing agent for a clay from Basra located in Iraq. This was done by adding four different percentages ranging from $0 \%$ to $15 \%$ in relation to the weight of the dry soil. The soil properties studied were Atterberg limits, unconfined compressive strength and compressibility. The results of the tests done determine that the liquid limit drops to a gypsum content of $3 \%$ and then raises. The plastic limit drops to $7 \%$ of the gypsum level and then raises. In addition, the maximum dry density drops while the optimal moisture content raises as the proportion of gypsum content increases. Unconfined compressive strength has also increased with the inclusion of recycled gypsum reaching the $5 \%$. The addition of $5 \%$ recycled gypsum increases the load capacity by approximately $167 \%$ compared to the load capacity of untreated gypsum [6].

The present work seeks to establish the effect that brick powder and gypsum have as an addition to a particular soil for civil engineering. This was done by adding both additions in defined proportions and subjecting the samples to laboratory tests under controlled conditions.

\section{Materials}

Three materials were used to produce this document. The first was the natural soil classified as a clay of high plasticity. The second was recycled brick powder (RBP) obtained from the grinding of recycled clay bricks. Finally, the third material was recycled gypsum powder (RGP) extracted from recycled gypsum plasterboards.

\subsection{Natural soil}

The soil used in this research comes from the South American Urbanization in Tala-Piura, Peru. According to its geotechnical properties, it was classified as a clay of high plasticity. The soil samples were extracted at a depth of $1.5 \mathrm{~m}$ to ensure that the specimens to be tested were less exposed to external agents that could affect their composition. The soil properties and the standards related to the obtaining of these are shown in Table 1.

\subsection{Recycled brick powder (RBP)}

The brick powder used in this investigation was obtained from masonry units made from clay. These pieces were collected from different construction sites, in which they were part of the usual waste. In order to turn the brick pieces into a fine powder that could be added to the clay soil, it was necessary to use a mechanical process that consisted of reducing the material into small pieces (approximately a maximum size of one inch) and then introduced into the Los Angeles abrasion machine. Finally, the pieces were washed and dried to obtain a powder free of impurities that 
could alter the effect of the addition on the clay. The resulting fine material was subjected to two laboratory tests. The first one was the moisture content test. The results showed that the brick dust had a moisture content of $0.8 \%$. This value may be considered low, but it is due to the characteristics of its fabrication. The second was the sieve granulometric test and was used to define the diameter of particles that would serve as additions. The results are shown in Table 2.

As shown in table 2, the diameters of the particles that compose the recycled brick powder vary from the sieve No. $40(0.426 \mathrm{~mm})$ to the sieve No. $200(0.074 \mathrm{~mm})$. On the other hand, the particles that compose the soil range from sieve No. $50(0.297 \mathrm{~mm})$ to sieve No. $200(0.074 \mathrm{~mm})$. In this way it can be stated that the diameter of the addition particles are the same diameters the natural soil mass has, ensuring that the added soil is finally a homogeneous material.

Table 1. Properties of natural soil

\begin{tabular}{|c|c|c|c|}
\hline \multicolumn{2}{|c|}{ Property } & Value & Standards \\
\hline 1 & Liquid limit (\%) & 52 & NTP - 339.129 \\
\hline 2 & Plastic limit (\%) & 25 & NTP - 339.129 \\
\hline 3 & Plasticity index & 27 & NTP - 339.129 \\
\hline 4 & Moisture content (\%) & 15.6 & NTP - 339.127 \\
\hline 5 & Gravel \% & 0 & NTP - 339.128 \\
\hline 6 & Sand \% & 17.9 & NTP - 339.128 \\
\hline 7 & Silt \% & 82.1 & NTP - 339.128 \\
\hline 8 & Maximum Dry Density $\left(\mathrm{g} / \mathrm{cm}^{3}\right)$ & 1.438 & NTP -339.142 \\
\hline 9 & Optimum Moisture Content $(\%)$ & 2.1 & NTP -339.142 \\
\hline 10 & Unconfined compressive strength $\left(\mathrm{kg} / \mathrm{cm}^{2}\right)$ & 6.3 & NTP -330.170 \\
\hline 11 & Soil classification (U.S.C.S) & CH & - \\
\hline
\end{tabular}

Table 2. Particle size distribution (RBP \& RGP)

\begin{tabular}{|c|c|c|}
\hline Sieve & Percentage retained (\%RBP) & Percentage retained (\%RGP) \\
\hline $\mathrm{N}^{\circ} 30$ & 0.0 & 0.0 \\
\hline $\mathrm{N}^{\circ} 40$ & 2.1 & 0.0 \\
\hline $\mathrm{N}^{\circ} 50$ & 4.1 & 0.0 \\
\hline $\mathrm{N}^{\circ} 80$ & 7.7 & 1.3 \\
\hline $\mathrm{N}^{\circ} 100$ & 13.6 & 7.7 \\
\hline $\mathrm{N}^{\circ} 200$ & 22.1 & 22.9 \\
\hline Bottom & 50.4 & 100.0 \\
\hline
\end{tabular}

\subsection{Recycled gypsum powder (RGP)}

The gypsum powder used in this research comes from the plasterboads used in the dry construction system, also known as "drywall". These plasterboards were collected from various construction sites, for which they represented part of the daily waste. To obtain only the gypsum and be able to separate it from the cellulose fibers and paperboard, to which it has been adhered since its fabrication, the material was reduced to smaller elements (approximately one inch in size) and introduced to the Los Angeles abrasion machine. In this way it was possible to obtain a recycled plaster powder. Finally, it was decided to subject the resulting material to two laboratory tests. The first was the moisture content test. The results indicated that the gypsum powder used had a moisture content of $1.5 \%$. Like brick dust, gypsum has a low moisture content due to its fabrication characteristics. To produce the gypsum plasterboards, this mineral is dried at high temperatures to make the material acquire volumetric stability. The second was the sieve granulometric test which served to define the diameter of particles that would enter the soil. The results are shown in Table 2.

As shown in Table 3, the diameters of the particles that compose the recycled gypsum powder vary from the No. 80 sieve $(0.177 \mathrm{~mm})$ to the No. 200 sieve $(0.074 \mathrm{~mm})$. On the other hand, the particles that compose the soil range from the No. 50 sieve $(0.297 \mathrm{~mm})$ to the No. 200 sieve 
$(0.074 \mathrm{~mm})$. The result of this test shows that the maximum diameter of the addition particles is less than the maximum diameter of the natural soil mass, ensuring that the added soil is finally a homogeneous material.

\section{Methodology}

The methodology used in this paper is divided into three stages: design of the dosages that will be used, preparation of the samples and tests performed.

\subsection{Design of the dosages}

To determine the quantity or percentage, that will be used, of the proposed stabilizing agents represents a fundamental part of any investigation with the aim of stabilizing a soil. In order to be able to propose a certain amount of addition, previous researches have been used to analyse two important aspects: what percentages of addition are used and with what amount the best results are obtained.

According to the information collected, the content of additions for the samples that were subjected to the laboratory tests can be visualized in Table 3 .

Table 3. Coding for added soil samples

\begin{tabular}{|c|c|c|c|}
\hline Dosage & Coding & OMC $(\%)$ & $\mathrm{MDD}\left(\mathrm{g} / \mathrm{cm}^{3}\right)$ \\
\hline Soil + 0\% Recycled gypsum + 0\% Brick powder & SN-00YSR-00PLR & 20.1 & 1.438 \\
\hline Soil + 2.5\% Recycled gypsum + 5\% Brick powder & SN-2.5YSR-05PLR & 20.4 & 1.5 \\
\hline Soil + 2.5\% Recycled gypsum + 10\% Brick powder & SN-2.5YSR-10PLR & 21.2 & 1.542 \\
\hline Soil + 2.5\% Recycled gypsum + 15\% Brick powder & SN-2.5YSR-15PLR & 22.2 & 1.548 \\
\hline Soil + 5\% Recycled gypsum + 5\% Brick powder & SN-05YSR-05PLR & 20.9 & 1.53 \\
\hline Soil +5\% Recycled gypsum + 10\% Brick powder & SN-05YSR-10PLR & 21.8 & 1.534 \\
\hline Soil + 5\% Recycled gypsum + 15\% Brick powder & SN-05YSR-15PLR & 22.5 & 1.54 \\
\hline Soil + 7.5\% Recycled gypsum + 5\% Brick powder & SN-7.5YSR-05PLR & 21.4 & 1.514 \\
\hline Soil + 7.5\% Recycled gypsum + 10\% Brick powder & SN-7.5YSR-10PLR & 22.3 & 1.521 \\
\hline Soil + 7.5\% Recycled gypsum + 15\% Brick powder & SN-7.5YSR-15PLR & 22.8 & 1.529 \\
\hline
\end{tabular}

\subsection{Tests performed}

The laboratory tests used were: Standard Proctor (MTC E-116) and Unconfined Compressive Strength (NTP-339.167). The Standard Proctor test was performed for each of the 9 proposed dosages. Initially, the sample was divided into 4 parts that were mixed, individually, with a certain amount of water. These samples were kept in plastic containers for 12 hours to ensure homogeneity in the moisture content of the total sample. Then, this material was placed into a mold with a diameter of $101.6 \mathrm{~mm}$ in three layers.

Each layer was compacted 25 times by a hammer released at a height of approximately $305 \mathrm{~mm}$ which exerts a force of $24.4 \mathrm{~N}$ and generates a compaction energy of $600 \mathrm{kN}-\mathrm{m} / \mathrm{m}^{3}$. Finally, with the data resulting from this test, a compaction curve was constructed that allowed us to find the Maximum Dry Density (MDD) and Optimum Moisture Content (OMC) values for each dosage.

The unconfined compressive strength test was also performed on all dosages. Towed specimens with a diameter of $100 \mathrm{~mm}$ and a height of $110 \mathrm{~mm}$ were used for this test.

In addition, a moisture content was used to achieve the maximum dry density, according to the results obtained from the standard Proctor test. Three samples were worked for each dose, making a total of 27 towed specimens that were also cured for 7 days.

Finally, the samples were subjected to a constant compressive force to find the breaking point and, subsequently, the unconfined compressive strength. The average of the three tests with the same sample will be accepted as the compressive strength for the dosage used. 


\section{Results and discussion}

\subsection{Compaction test}

The results of the Proctor compaction test are shown graphically in FIGURE I and analytically in Table 3. According to these results, the maximum dry density (MDD) increases as the percentage of gypsum and ceramic powder added increases for all dosages.

The soil in its natural state has a maximum dry density of $1438 \mathrm{~g} / \mathrm{cm}^{3}$. The maximum dry density reached by the added soil is $1,548 \mathrm{~g} / \mathrm{cm}^{3}$ which corresponds to the dosage "SN-2.5YSR15PCR" and the minimum dry density reached by the added soil is $1.5 \mathrm{~g} / \mathrm{cm}^{3}$ for a dosage of "SN-2.5YSR-05PCR". This means a maximum increase of $7.65 \%$ and a minimum increase of $5.29 \%$ in this parameter. This is due to the fact that the percentage of soil that was replaced, from the sample, had less specific gravity with respect to the additions that finally replaced it, for this reason the soil has reached a higher volumetric weight.

Furthermore, there was also an increase in the optimum moisture content of the tested sample. The moisture content in which the soil reaches its maximum dry density in natural soil is $20.1 \%$. The optimal maximum moisture content is $22.8 \%$ which corresponds to the dosage "SN-7.5YSR15PCR" and the minimum is $20.4 \%$ which corresponds to the dosage "SN-2.5YSR-05PCR".

The increase shown for all dosages means that the soil mass has increased the capacity to retain water between its particles as the percentage of gypsum and ceramic dust increases. This is because a portion of the soil has been replaced by two additions that have finer particles, thus generating a greater specific surface area that results in an increase in the moisture needed for the added soil to reach its maximum dry density.

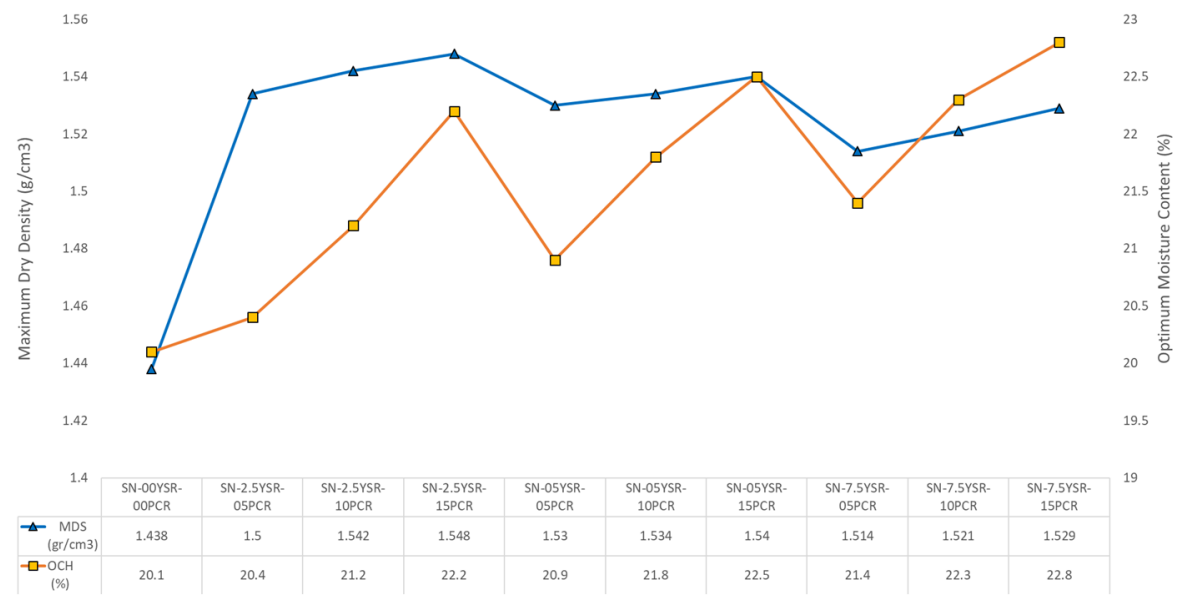

Fig. 1. Soil compaction parameters

\subsection{Unconfined compressive strength test}

To evaluate the performance of the additions proposed in this laboratory test, the added soil has been divided into groups defined by their gypsum content: (Fig. 2) natural soil with $2.5 \%$ gypsum and brick powder, (Fig. 3) natural soil with $5 \%$ gypsum and brick powder, and (Fig. 4) natural soil with $7.5 \%$ gypsum and brick powder.

In the first group are the natural soil and the first three proposed additions: SN-00YSR-00PCR, SN-2.5YSR-05PCR, SN-2.5YSR-10PCR and SN-2.5YSR-15PCR. To perform this test, 3 specimens were made for each dosage, then cured for 7 days and finally tested. The compression resistance of the natural soil has an average value of $6.3 \mathrm{~kg} / \mathrm{cm}^{2}$, while the maximum average resistance reached in this first group has a value of $23.1 \mathrm{~kg} / \mathrm{cm}^{2}$ for the dosage "SN-2.5YSR15PCR". With this premise it can be stated that the soil increased its resistance to unconfined 
compression by $266.7 \%$.

In the second group is the natural soil again, and the dosages containing $5 \%$ gypsum: SN-00YSR-00PCR, SN-05YSR-05PCR, SN-05YSR-10PCR and SN-05YSR-15PCR. The compression resistance of natural soil has an average value of $6.3 \mathrm{~kg} / \mathrm{cm}^{2}$, while the maximum average resistance reached in this first group has a value of $26.6 \mathrm{~kg} / \mathrm{cm}^{2}$ for the dosage "SN-05YSR-15PCR". The results shown show that the resistance to soil compression increased by $322.2 \%$ compared to the resistance obtained with natural soil.

In the third group is the natural soil again, and the dosages containing $7.5 \%$ gypsum: SN-00YSR-00PCR, SN-7.5YSR-05PCR, SN-7.5YSR-10PCR and SN-7.5YSR-15PCR. The compression resistance of natural soil has an average value of $6.3 \mathrm{~kg} / \mathrm{cm}^{2}$, while the maximum average resistance reached in this first group has a value of $28.8 \mathrm{~kg} / \mathrm{cm}^{2}$ for the dosage "SN-7.5YSR-15PCR". The results shown evidence that the resistance to soil compression increased by $357 \%$ compared to the resistance obtained with natural soil.

The increase in compressive strength for all the remodeled and tested dosages is due to the formation of new cementitious materials as a result of the additions used.

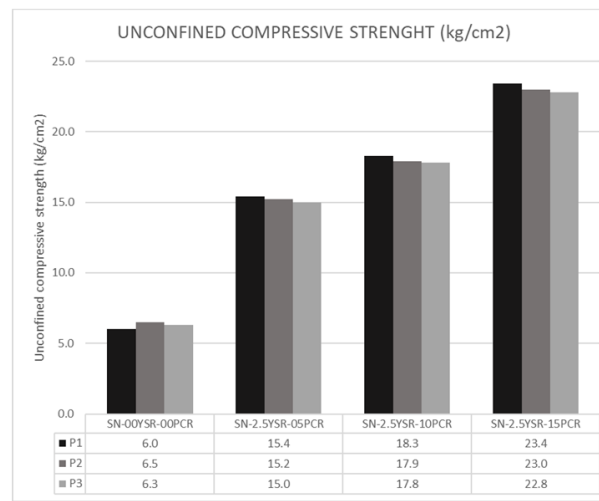

Fig. 2. Natural soil with $2.5 \%$ gypsum and brick powder

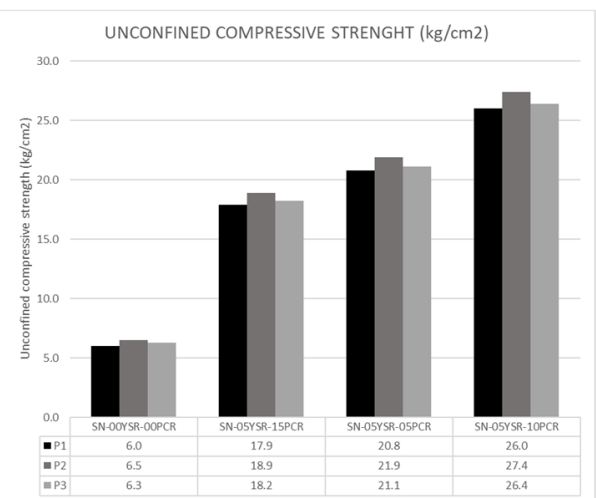

Fig. 3. Natural soil with $5 \%$ gypsum and brick powder

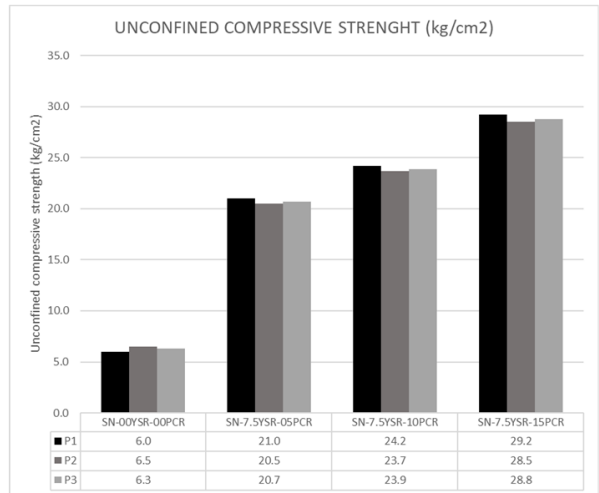

Fig. 4. Natural soil with $7.5 \%$ gypsum and brick powder

\section{Conclusions}

Based on the results obtained from the laboratory tests performed, it was concluded that:

1) Compaction parameters were improved with the addition of recycled brick powder RBP and recycled gypsum powder RGP.

2) The maximum dry density increased from $1438 \mathrm{~g} / \mathrm{cm}^{3}$ to $1548 \mathrm{~g} / \mathrm{cm}^{3}$. This is due to the incorporation of two additions with higher specific gravity, in comparison to the natural soil. 
3) The moisture content, in which the soil reaches its maximum dry density, increased from $20.1 \%$ to $22.8 \%$. This is due to the fact that the added soil particles have increased their capacity to retain water, since the particles that compose the additions have a greater specific surface area.

4) The compressive strength of the soil increased for all the proposed dosages. The natural soil reached a strength of $6.3 \mathrm{~kg} / \mathrm{cm}^{2}$ and maximum strength achieved due to RBP and RGP additions was $28.8 \mathrm{~kg} / \mathrm{cm}^{2}$, approximately $322.2 \%$. This is mainly due to the chemical reaction generated by water with RGP particles and the formation of cementitious materials by RBP particles.

These results demonstrate the effectivity of RBP and RGP for the stabilization of a clay soil and propose both materials as an effective, efficient, and sustainable alternative to the geotechnical problems generated by problematic soils similar to the one studied in this research work.

\section{References}

[1] James J., Kasinatha Pandian P. Effect of micro ceramic dust on the plasticity and swell index of lime stabilized expansive soil. International Journal of Applied Engineering Research, Vol. 10, Issue 42, 2015, p. 30647-30650.

[2] Akhtar Hossain Md. Improvement of strength and consolidation properties of clayey soil using ceramic dust. American Journal of Civil Engineering, Vol. 7, Issue 2, 2019, p. 41.

[3] Al-Bared M. A. M. Sustainable strength improvement of soft clay stabilized with two sizes of recycled additive. International Journal of Geomate, Vol. 15, Issue 51, 2018, p. 2186-2990.

[4] Enshassi A., Kochendoerfer B., Rizq E. Evaluación de los impactos medioambientales de los proyectos de construcción. Revista Ingeniería De Construcción, Vol. 29, Issue 3, 2014, p. 234-254.

[5] Cabalar A. F., Hassan D. I., Abdulnafaa M. D. Use of waste ceramic tiles for road pavement subgrade. Road Materials and Pavement Design, Vol. 18, Issue 4, 2016, p. 882-896.

[6] Al-Adili A., Salim N. M., Al Soudany K.-Y. Response of soft soil mixing with recycled gypsum (plasterboard) as stabilized agent for soil underneath oil tank as a case study. IOP Conference Series: Materials Science and Engineering, Vol. 579, 2019, p. 012048. 